\title{
Da educação fascista à educação da classe trabalhadora: um diálogo com Antônio Gramsci
}

\author{
From fascist education to working class education: a dialogue with Antônio \\ Gramsci
}

\author{
Márcia Magalhães ${ }^{1 *}$, Pedro Santos ${ }^{1}$, Escolástica Santos ${ }^{1}$
}

\begin{abstract}
RESUMO
O presente trabalho tem como objetivo apresentar uma discussão sobre o conceito de educação segundo o prisma fascista e na perspectiva gramsciana. Para tanto, utilizamos a metodologia de abordagem qualitativa e de procedimento bibliográfico compreendida por Gil (2002) como aquela realizada a partir de materiais já existentes como revistas, periódicos, jornais, etc. Ademais, para apropriação do material de estudo selecionado, usamos a técnica de leitura imanente de Lessa (2014) que visa impedir que nossas impressões e sensações individuais interfiram na interpretação das ideias defendidas por um determinado autor. Para a compreensão do pensamento de Antonio Gramsci sobre a educação no contexto fascista italiano, utilizamos a Técnica Análise Textual Discursiva (ATD) de Moraes (2003) que possui três etapas: unitarização, categorização e comunicação. Por fim, entendemos que a educação a partir da ótica fascista visa manter a condição de subalternidade da classe trabalhadora e preservar o status quo dos grupos historicamente privilegiados. Já uma educação comprometida com o viés revolucionário tem como horizonte a emancipação dos sujeitos subalternos a fim de que sejam capazes de construir uma outra ordem social.
\end{abstract}

Palavras - chave: Educação fascista, Educação Gramsciana, Emancipação humana.

\begin{abstract}
The present work aims to present a discussion about the concept of education according to the fascist perspective and in the gramsciana perspective. To this end, we used the methodology of qualitative approach and bibliographic procedure understood by Gil (2002) as that performed from existing materials such as magazines, journals, journals, etc. In addition, for appropriation of the selected study material, we use the immanent reading technique by Lessa (2014), which aims to prevent our individual impressions and sensations from interfering in the interpretation of the ideas defended by a particular autho. To understand the thought of Antonio Gramsci about education in the Italian fascist context, we use the Technical Discursive Textual Analysis (ATD) of Moraes (2003), which has three stages: unitarization, categorization and communication. Finally, we understand that education from the fascist perspective aims to maintain the condition of subordinate working class and preserve the status quo of historically privileged groups. An
\end{abstract}

\footnotetext{
${ }^{1}$ UFPI - Universidade Federal do Piauí. *E-mail: marciamagalhaes989@gmail.com
} 
education committed to the revolutionary bias has as its horizon the emancipation of subordinate subjects so that they are able to build another social order.

Keywords: Fascist education. Gramscian Education. Humam emancipation.

\section{INTRODUÇÃO}

O presente trabalho tem como escopo apresentar uma discussão, mesmo que breve, sobre o conceito de educação segundo o prisma fascista e também na perspectiva gramsciana. Demonstramos que uma educação fascista tem como fim validar o contexto econômico, político, social e cultural que cerceia o ímpeto criador das classes subalternas. E uma das formas de submetê-las é pelo viés educacional, que contribui para que os subalternizados aprendam a respeitar as autoridades, a não criticar o sistema de dominação, a acatar as normas instituídas, a defender uma visão fatalista de que o mundo é assim mesmo e não poder ser modificado e a aceitar a ideia de que são inaptas para a atividade intelectual e aptas apenas para as atividades manuais.

Entendemos que, na contramão dessa concepção de educação, existe outra que é comprometida com a classe trabalhadora, pois pretende contribuir no seu processo de elevação intelectual e moral. Isso significa que esse processo educativo tem como fim mediar a superação da condição de subalternidade dos sujeitos históricos a fim de que se tornem mestres de si mesmos. Essa mediação modifica os sujeitos e os comprometem na luta pela transformação substantiva do ordenamento do capital, visando a conquista de uma nova sociedade regulada pelos produtores de toda a riqueza existente.

Para tanto, utilizamos a metodologia de abordagem qualitativa e de procedimento bibliográfico. Gil (2002) entende esse procedimento como aquele que visa analisar materiais já existentes, como publicações periódicas, revistas, jornais, livros, dentre outros. Assim, selecionamos o material de pesquisa que foi apropriado com base na leitura imanente de Lessa (2014).

E foi nesse sentido, que utilizamos essa técnica a fim apropriar e interpretar, de forma a mais fidedigna possível, o pensamento de Antônio Gramsci sobre a educação no contexto fascista gramsciano. Desse modo, realizamos os fichamentos literais dos escritos pré-carcerários e de alguns cadernos carcerários (11, 12, 19 e 25), que foram organizados numa pasta para posterior análise e interpretação. 
Para essa etapa, utilizamos a Técnica Análise Textual Discursiva (ATD) de Moraes (2003), que possui três etapas: unitarização, categorização e comunicação. Na primeira, o pesquisador faz uma desconstrução, isto é, uma análise detalhada de todo corpus (documentos e textos) a ser investigado. Na segunda, ele estabelece relações e comparações entre dados e informações a fim de categorizá-las. E na terceira, elabora-se um novo texto (metatexto) com base na apropriação do que foi lido e analisado.

Exposto isto, apresentaremos a seguir a discussão sobre a educação na perspectiva fascista e no ponto de vista gramsciano. Esperamos, assim, que nosso trabalho possa contribuir para a compreensão crítica do contexto histórico atual, marcado profundamente pelo discurso de extrema direita que propaga a violência contra as subjetividades antagônicas e, que fortaleça a luta por uma educação comprometida com o processo de afirmação do ser humano como mestre de si mesmo.

\section{A educação na perspectiva gramsciana versus a educação fascista}

A educação, na perspectiva gramsciana, emerge como instrumento de luta que visa contribuir para o desenvolvimento intelectual e moral da classe trabalhadora a fim de instaurar uma nova forma de sociabilidade humana. Diferente do que muitos pesquisadores pensam, a educação em Gramsci não assume uma função secundária em relação a outros temas, como Estado, hegemonia, sociedade civil, reforma, contrarreforma, revolução passiva, dentre outros. Pelo contrário, ela é relevante porque articulada a outros conceitos, contribui para construção de uma nova formação social.

Mas, convém ressaltar que o tipo de educação predominante num determinado contexto histórico depende dos interesses econômico, político, social e cultural dos sujeitos históricos que disputam posição na arena social. Nesse sentido, os que vencem a disputa tendem a definir um modelo de educação alinhado a sua concepção de mundo.

Isso ocorreu na Itália que saiu da Primeira Guerra Mundial (1914-1918) profundamente devastada econômica, política e socialmente. $\mathrm{O}$ aumento do desemprego, sobretudo da classe trabalhadora, desencadeou fortes manifestações por todo o país, ocasionando uma crise hegemônica. E foi nesse cenário que o fascismo surgiu com a promessa de solucionar essa crise que, para Gramsci, não era algo especificamente italiano, mas próprio de todo o sistema do capital. 
Gramsci (2004, p. 282) entende que quando a democracia burguesa percebeu que não podia mais resistir à pressão da classe trabalhadora, mesmo que em um quadro de liberdades apenas formais, organizou o fascismo que "desagregando a classe operária, voltou a dar possibilidade de existência à 'democracia'”. As aspas significam que, mesmo essa democracia burguesa sendo anunciada pelo fascismo, teve a sua existência comprometida na medida em que questionava o poder autoritário.

Nesse sentido, o fascismo foi apoiado inicialmente pela pequena burguesia como forma de poder político para dar respostas ao cenário desastroso do pós guerra e anular o que era denominado na época de ameaça socialista. Acontece que diversos apoiadores desse movimento contrário à classe trabalhadora, foram também vítimas quando posteriormente faziam críticas ao poder instituído.

Assim, o fascismo não é um regime que surge da classe trabalhadora, mas de frações da burguesa que cientes da ameaça da sua condição de classe, atacam as conquistas parciais democráticas dos subalternos e instauram uma política predominantemente autoritária. Desse modo, a classe burguesa tende a defender tanto o pensamento autoritário para se preservar em um momento de profunda crise, como também a democracia em tempos que consegue manter a sua hegemonia.

Noutros termos, democracia burguesa e regime totalitário são diferentes, mas podem ser utilizados como meios pela classe dominante a fim de se perpetuar no poder. Isso significa que os direitos conquistados pela classe trabalhadora podem ser relativamente garantidos, desde que não ameacem a existência dos que governam.

É no momento de intensificação da crise em que os governantes percebem o risco de deixarem de ser, que imediatamente tendem a se articular para negar os direitos legalmente conquistados pelos trabalhadores e, para tanto, podem adotar a política do ódio e da intolerância.

Gramsci (2004, p. 85) compreende que a legalidade e a ilegalidade se articulam em prol da classe que detém o poder. Pela via legal, ela exerce o poder e garante direitos parciais aos subjugados. Mas, ao se ver ameaçada, utiliza-se também da ilegalidade, da violência e do terror cometidos contra os que a combatem.

Uma a uma, as prefeituras foram sendo arrancadas pela violência das mãos da classe operária; as organizações foram dissolvidas com o uso da força armada; a classe operária e camponesa foi expulsa das posições conquistadas, a partir das quais ameaçava para além da conta a existência da propriedade privada. Surgiu assim o fascismo, que se afirmou e impôs fazendo da ilegalidade a única coisa legal. Nenhuma 
organização, salvo a fascista; nenhum direito de voto, a não ser quando dado aos representantes dos latifundiários e dos industriais. É esta a legalidade que a burguesia reconhece quando é obrigada a repudiar a legalidade formal.

O fascismo italiano surgiu a partir da ilegalidade de todas as organizações operárias legalizadas pelo aparato democrático burguês. A ilegalidade, nesse contexto, tornou-se a regra para atacar e destruir a luta da classe trabalhadora. Assim, as suas organizações que eram regulamentadas juridicamente foram declaradas ilegais, enquanto que os atos de violência e ódio obtiveram reconhecimento jurídico em benefício da classe burguesa.

No fascismo imperou a legalização do que antes era tido como ilegal e a ilegalidade do que se tinha como legal no âmbito jurídico. Essa mudança em que o ilícito obtém legitimidade e o lícito perde o seu caráter de legalidade, ocorre em razão da manutenção do status quo da classe dominante.

É com base na legalidade do que era ilegal, que grupos fascistas italianos assassinavam líderes de associações da classe trabalhadora, incendiavam bibliotecas e perseguiam os membros do Partido Comunista Italiano (PCI), que usavam pseudônimos para não serem identificados pelo regime intolerante de Mussolini.

A promulgação de leis fascistas em 1925 proibiu as liberdades individuais e de impressa e tornou ilegal as organizações políticas proletárias, como partidos, sindicatos, comitês, dentre outros. Em 1926, a prisão de Gramsci, líder do PCI, deixou órfã a principal e maior organização de combate ao autoritarismo fascista, caracterizando assim, a desagregação da classe trabalhadora.

Para Gramsci (2004, p. 229), o capitalismo e o fascismo pressupõem que a classe trabalhadora seja privada de sua função de guia das demais classes oprimidas historicamente. Por isso, ambos desagregam suas organizações que exercem "uma influência revolucionária sobre todos os oprimidos e retira do governo a base democrática do poder”. O que significa que todos os direitos conquistados, via democracia burguesa, são jogados no âmbito da ilegalidade.

Todavia, para o filosofo sardo, mesmo que as organizações operárias representem uma ameaça constante aos capitalistas e fascistas, ambos não as destroem totalmente. Os primeiros não as eliminam por completo devido razões industrias, pois precisam dessas instituições para conquistarem o consenso dos trabalhadores a fim de obterem êxito na produção. Já os fascistas mantinham essas organizações, com o mínimo 
de autonomia, para propagarem a sua ideologia de "estado acima de todos", fazendo reformas legais para a conquista da classe trabalhadora, como a Carta del Lavoro de 1927 que criou o Tribunal do Trabalho que promoveu o corporativismo, sistema de alianças entre capital e trabalho para minimizar o conflito entre capitalistas e operários (GRAMSCI, 2004).

É nesse contexto marcado profundamente pela intolerância que Gramsci (2004) defende intensamente a necessidade de organização da classe trabalhadora, mesmo diante dos limites impostos pelo fascismo via força coercitiva e também pelo consenso. Não foi à toa que Mussolini fez investimentos nos meios de comunicação, indústria cinematográfica e na educação escolar por meio da reforma Gentile, visando promover a propagação da ideologia fascista.

Isso demonstra que o fascismo é um regime que combina força e convencimento a fim de se legitimar como uma nova concepção de mundo. Gramsci foi um dos membros do PCI que mais levou a sério o processo de desenvolvimento dessa concepção na Itália. Diversas vezes alertou os companheiros de partido para a ameaça às bandeiras de luta da classe trabalhadora.

Ciente dos ataques à luta da classe trabalhadora, Gramsci tentou fortalecê-la por meio da mobilização política, da criação do Jornal L'Ordine Nuovo e da realização de cursos por correspondência. Lutou com todas as suas forças contra uma ideologia que pregava o ódio ao socialismo, à pluralidade de pensamento, às lutas e às formas de organização da classe trabalhadora.

A concepção de Gramsci (2004, p.75) sobre o fascismo é profunda, pois o compreende para além da aparência. Pela sua análise, percebe que o Estado italiano é o hospedeiro do fascismo contra a classe trabalhadora. $O$ pensador não se deixa enganar pelo discurso que defende o Estado como instância do universal que governa para todos indistintamente. Pelo contrário, desvela-o como esfera de caráter particular, pois está a serviço dos interesses de alguns privilegiados:

[...] É preciso não deixar que se creia que basta um pequeno esforço para salvar-se dos perigos que hoje ameaçam todo o povo trabalhador. É preciso fazer compreender, é preciso insistir para fazer compreender que o proletariado hoje não tem contra si apenas uma associação privada, mas todo o aparelho estatal, com sua polícia, seus tribunais, seus jornais que manipulam a opinião segundo o arbítrio do governo e dos capitalistas [...]". 
Para o filósofo sardo, o fascismo tinha a seu favor o poder estatal, constituído tanto pelos aparatos políticos, como também pelos aparatos privados de hegemonia, como os jornais, as escolas, as universidades e os partido políticos que, alinhados com os interesses capitalistas, manipulavam a opinião pública.

Nessa direção, Gramsci afirmava no jornal Avanti de 1920, que jamais se deve confiar no ideal socialdemocrata de restauração do Estado burguês como alternativa para superar o autoritarismo fascista:

O fascismo italiano incendiou o Avanti! de Milao e de Roma, o Proletário de Pola e o Lavoratore de Triste, sem que nenhum fascista tenha sido punido: o Estado restaurado não mais incendiará jornais, mas os suprimirá "legalmente". O fascismo assaltou Câmaras do Trabalho e prefeituras socialistas: o Estado restaurado dissolverá "legalmente" as Câmaras de Trabalho e as prefeituras que pretendam continuar socialistas. O fascismo assassina os militantes da classe operária; o Estado restaurado os mandará "legalmente" para a prisão e, restaurada também a pena de morte, os fará assassinar por um novo funcionário governamental: o carrasco. Este desenvolvimento é universal; já ocorreu parcialmente e continuará a se desenvolver também na Itália (GRAMSCI, 2004, p. 429-30).

Para Gramsci, o fascismo é uma alternativa utilizada pela burguesia para se manter no poder. Assim, o início do seu processo de desenvolvimento caracteriza-se pela ilegalidade na medida em que a violência praticada contra a classe operária contrariava os princípios legais instituídos. Mas, a partir do momento que o fascismo se consolida, o mesmo Estado que antes considerava essa concepção político-ideológica como ilegal, legaliza-o na contramão dos interesses da classe trabalhadora.

Assim, compreendia que a restauração do Estado burguês defendida por muitos partidos políticos, dentre eles, frações do Partido Socialista Italiano (PSI), legalizaria a violência fascista. O que significa que com a restauração, em vez de os fascistas incendiarem jornais e sedes de organizações operárias, estas seriam declaradas ilegais. Em vez de assassinar militantes da classe operária, esses seriam presos legalmente. Ademais, nada mais seria ilegal, exceto o combate ao autoritarismo legalizado.

Gramsci entendia ainda que a frágil formação da classe trabalhadora e a ausência de um partido político forte, fundamentado na teoria revolucionária, são alguns fatores que dificultam o velho morrer para o novo nascer. Isto é, para o Estado burguês ser superado, precisa nascer a nova sociedade emancipada fundada pela classe trabalhadora. 
Mas, enquanto o novo não nasce e nem o velho consegue ser superado, surgem diversas forças reacionárias como o fascismo para a manutenção da velha ordem social.

Decerto, o pensador italiano estava ciente de que era necessária a construção de uma nova hegemonia. Santos (2017) compreende que - embora a hegemonia não apareça explicitamente nos escritos pré-carcerários - Gramsci já sinalizava para a construção desse conceito na medida em que propunha a união dos trabalhadores industriais do norte e camponeses do sul da Itália para lutarem contra o ordenamento do capital. Dias (1996, p. 36) depreende que a hegemonia consiste em um: “[...] projeto que permite expressar o programa, o horizonte ideológico, no qual as demais classes se movem. Horizonte que ao proceder à padronização ao "conformismo" desorganiza, inviabiliza, ou tenta, os projetos das demais classes $[\ldots] "$.

Para esse autor, a classe que detém o poder hegemônico exerce seu horizonte ideológico sobre as demais, visando desarticulá-las para as articular ao programa político dominante. Hegemonia é uma concepção de mundo particular, pois emerge de uma determinada classe social, mas que é absorvida por diversos segmentos sociais. Desse modo, a ideologia da classe dominante é assumida por parte significativa dos sujeitos sociais de uma dada sociedade.

É nesse sentido, conforme esse mesmo autor, que a hegemonia é concebida como uma racionalidade que se tornou histórica, pois resultou do esforço psicofísico da classe dominante para conquistar os subalternos.

Compreendemos que, pelo conceito de hegemonia, Gramsci demonstra à classe trabalhadora que as ideias, as crenças e os valores não caem do céu na cabeça dos sujeitos históricos. Pois, elas emergem das condições materiais e expressam interesses de determinados grupos e classes sociais. Além disso, ensina também que o pensamento é uma construção e que pode ser modificado na direção do horizonte da emancipação humana.

Nesse sentido, Gramsci é um educador que educa a classe trabalhadora e que também aprende na convivência com ela. É nessa relação que ele compreende a necessidade de a classe subalterna reelaborar a sua própria concepção de mundo a fim de se tornar a mestra de si mesma. Isto significa que ao invés de ela absorver de forma acrítica a concepção de mundo alheio, precisa esforçar-se para pensar criticamente por si mesma para assumir a posição de governante de uma nova forma civilizatória. 
Para tanto, precisa criar para si seus próprios intelectuais orgânicos, que são os que conectados com a classe e grupos subalternos, elaboram e difundem uma nova ideologia que cimenta a construção da sociedade regulada pelos produtores associados. Assim, Gramsci tem como horizonte esse novo ordenamento social que precisa ser construído, difundido, apropriado e reelaborado dialeticamente para o fortalecimento de uma nova hegemonia, entendida como a racionalidade construída a partir da luta das classes e grupos subalternos.

Nessa luta pela construção da nova hegemonia, Gramsci (2004) entendia bem que a burguesia se constituiu enquanto classe, porque tinha os seus próprios intelectuais. Estes foram criados pela classe que representavam e foram responsáveis também pela criação da consciência que essa mesma classe devia ter acerca da sua posição de governante e dirigente na sociedade.

Dias (1996) compreende que a burguesia possui melhores condições financeira e cultural para formar os seus intelectuais do que a classe trabalhadora. A primeira garante uma formação que prepara os seus jovens para assumirem a posição de governantes, enquanto mantém os filhos da classe trabalhadora na condição de governados.

A segunda possui imensas dificuldades financeiras para investir na formação dos seus próprios intelectuais para contribuírem no processo de fortalecimento da luta revolucionária. Além disso, muitos deles correm o risco de serem formados e, posteriormente, cooptados pelo poder instituído.

Mesmo assim, Gramsci (2004) defendia que a classe e grupo subalternos tivessem os seus próprios intelectuais comprometidos com o horizonte da emancipação humana. A formação desses intelectuais contribui para o maior fortalecimento teórico, técnico e científico da classe trabalhadora na luta pela construção da sociedade regulada.

Nesse sentido, a educação da classe trabalhadora manifesta-se como uma questão relevante no pensamento gramsciano. Ela não é secundarizada, porque se articula a outras dimensões do real, visando contribuir para a construção de uma nova forma de sociabilidade humana. E Gramsci (2004), mesmo num cenário social marcado pela intolerância, pela ilegalidade e pela legalização de atos violentos contra os trabalhadores, defendia uma educação política, capaz de desvelar os diversos condicionantes que contribuíam para a ameaça da existência de sujeitos históricos pelo regime fascista.

Gramsci (2004) compreendia que a educação política era uma das condições para a fundação da nova ordem social. Para tanto, o líder do Partido Comunista Italiano (PCI) 
defende a ampla função educativa do partido político no sentido de contribuir para unificar camponeses pobres do sul e operários industriais do norte, expondo as contradições do regime fascista. Assim, o autor sardo compreende, nos Escritos préCarcerários (1921-1926), o partido da classe trabalhadora como intelectual coletivo, porque formado por diversos sujeitos com consistente formação teórica, técnica, científica e política, articulam os subalternos para construírem uma nova ordem social.

Em um escrito de 1926, Gramsci (2004, p. 446) afirma que “[...] a sociedade meridional é um grande bloco agrário constituído por três estratos sociais: a grande massa camponesa amorfa e desagregada; os intelectuais de pequena e média burguesia rural; e os grandes proprietários agrários e os grandes intelectuais [...]".

Os camponeses do sul, que compunham a maior parte da população meridional, eram uma massa desagregada porque não possuíam uma coesão entre si devido à escassez de intelectuais que a unificasse. Ao contrário da pequena e média burguesia rural e dos grandes proprietários agrários e industriais, seus intelectuais contribuíam para sua unificação, além de exercerem influência sobre os camponeses.

Desse modo, na sociedade meridional o intelectual era o principal elemento de ligação entre os grandes proprietários agrários e os camponeses subjugados.

O camponês meridional liga-se ao grande proprietário rural através do
intelectual. Os movimentos camponeses, na medida em que não se
expressam em organizações de massa ainda que só formalmente
autônomas e independentes [...] terminam por se enquadrar sempre nas
instituições normais do aparelho estatal - prefeituras, governos
provinciais, Câmara dos Deputados - através de composições e
decomposições dos partidos locais, cujos quadros são formados por
intelectuais, mas que são controlados pelos grandes proprietários e por
seus homens de confiança [...]. (GRAMSCI, 2004, p. 426-427)

Assim, os camponeses que não possuíam organizações independentes e nem intelectuais comprometidos com as suas pautas, enquadravam-se em instituições burguesas controladas pelos grandes proprietários de terra. Para o pensador sardo, a frágil presença de intelectuais orgânicos da classe trabalhadora no sul italiano era uma das causas da sua fragmentação.

Isso ocorria, em larga medida, porque os intelectuais da classe dominante visavam enfraquecer as inciativas de luta dos subalternos e, em contraposição, fortalecer a ideologia da classe a que se vinculavam. Nesse sentido, a atividade desses intelectuais 
possui dupla função, que é desarticular os simples e, ao mesmo tempo, articulá-los conforme a lógica do poder dirigente e dominante.

Nessa análise de Gramsci (2004) sobre a situação meridional, desvela-se não apenas a razão de ser da precária articulação da classe trabalhadora, como também se demonstra a necessidade de uma luta consciente e disciplinada para articulá-la em prol do horizonte revolucionário.

O pensador italiano compreendia que, nessa região, a produção intelectual era majoritariamente restrita a pequenos grupos burgueses. Não existiam revistas e nem editoras que agrupassem produções de pequenos e médios intelectuais meridionais. Em decorrência disso, os sulistas e os seus problemas sociais eram retratados no país conforme o viés ideológico dominante.

Gramsci (2015), no Caderno 25, aprofunda essa discussão acerca da lógica da classe dominante que historicamente subjuga os simples. Ele afirma que a história dos grupos sociais subalternos é marcada pela desagregação, pela fragmentação e pela visão negativa acerca dos sujeitos menos privilegiados. Esse fracionamento não é visto como algo próprio dos subalternos, mas como resultado da intervenção dos grupos e classes dominantes que pretendem manter o seu status quo.

Assim, a dificuldade de articulação dos subalternos requer a compreensão das forças antagônicas que tendem a anular o novo que pretende nascer. Isso significa que as forças econômica, política, social e cultural que sustentam a velha ordem do capital reagem diante da possibilidade do devir de um novo ordenamento social, fragmentandoo em prol do sistema vigente.

Gramsci (2004) compreendia que essa desarticulação da luta dos subalternos resulta do embate de correlações de forças e da atividade dos intelectuais da classe dominante que contribuem nessa direção. Esses intelectuais dificultam a organização política dos simples para mantê-los subservientes ao ordenamento do capital. Desse modo, o autor alerta-nos que as rebeliões dos grupos subalternos sofrem as interferências e perseguições dos que dominam e dirigem.

Mas, ressaltamos que essa intervenção não anula de forma absoluta a possibilidade de construção da unidade política dos subalternos. Para Gramsci (2004), o partido da classe trabalhadora, que é o intelectual coletivo, precisa estar ciente das forças antagônicas e, ao mesmo tempo, tornar-se uma nova disciplina que a orienta, motiva-a e a mobiliza a fim de superar o projeto societário burguês. 
A unidade dos grupos e classes subalternas requer a atividade educativa do seu intelectual, visando fragilizar e extinguir a ideologia burguesa para instituir e fortalecer a concepção de mundo construída pelos subalternos. Assim, para que os grilhões da subordinação sejam superados faz-se necessária a ampla formação de intelectuais, homens e mulheres, capazes de unificar o proletariado para recontarem e recriarem a sua própria história.

Gramsci (2004), em seu texto intitulado Homens ou Máquinas, critica a concepção estrita de cultura ${ }^{2}$, tida como saber erudito acessível a alguns privilegiados. Segundo o autor, essa visão que reduz a cultura à erudição - que é peculiar de uma sociedade de classe- valida a dicotomia entre os que sabem e governam e os que nada ou pouco sabem e são governados.

Nessa direção, os filhos da burguesia que têm acesso à parte significativa do acervo material e cultural são concebidos como eruditos e aptos para governarem, enquanto os filhos dos proletariados são vistos geralmente como ignorantes e incapazes para o exercício de cargos de comando. Ou seja, a concepção de cultura supracitada mantém a relação de poder entre governantes e subalternidade.

Todavia, para o filosofo italiano, todos devem ter acesso à cultura, entendida não como privilégio de alguns, mas como acervo material e cultural produzido historicamente pela humanidade. Para tanto, a luta da classe trabalhadora deve ser pela superação da sociedade de classe e pela educação desinteressada, que é processo formativo integral que visa à elevação intelectual e moral de homens e mulheres e que não se restringe ao exercício de um oficio profissional.

Essa educação comprometida com a emancipação humana é contrária àquela que valida o fascismo, o liberalismo, o fordismo e o americanismo da época de Gramsci. Decerto, o que ele propõe é um processo educativo na contracorrente do modelo educacional proposto pelo filósofo Gentile, que defendia a cisão entre os intelectuais e o povo.

Para Semeraro (2021), interpretando Fini (2008), o pensamento idealista de Gentile, ministro da educação de Mussolini, defendia a cisão não apenas entre teoria e prática, como também entre os que governam e os que são governados. Para os primeiros,

\footnotetext{
${ }^{2}$ Gramsci não entende a cultura apenas como erudição, mas como um conjunto de saberes eruditos ou não, produzidos historicamente por homens e mulheres.
} 
propunha-se o curso superior a fim de que se tornassem a elite dirigente e, para os últimos, a formação profissional voltada para o adestramento manual e industrial.

Decerto, Gramsci (2004) compreendia que a razão de ser da fratura entre governantes e governados estava para além da esfera educacional. Diferente de muitos pesquisadores no contexto atual que pretendem resolver a fragmentação entre teoria e prática como um problema, sobretudo de cunho político e epistemológico, o pensador italiano a explicava a partir da relação dialética entre estrutura e superestrutura. Isto significa que a fratura entre o pensamento e ação pressupõe a reflexão crítica sobre o modo por meio do qual os sujeitos históricos produzem a sua existência.

No campo da produção, os sujeitos sociais encontram-se divididos entre os que compram a força de trabalho e os que a vendem. Aqueles se encontram em condições privilegiadas são os donos dos meios de produção e podem usufruir da riqueza material e cultural produzida pela humanidade para exercerem a função de governantes. Já os que vendem a sua energia psicofísica para se manterem vivos, tornam-se subalternos na medida em que lhes é negada a formação teórica, técnica e científica para interpretação e intervenção no mundo.

Desse modo, Gramsci (2004) compreendia que o dualismo da reforma educacional de Gentile - que se expressava pela defesa do ensino superior para a elite e o ensino profissional para os subalternos - requer a compreensão crítica do antagonismo de classes que fundamenta as relações sociais de produção da sociedade burguesa. Nesse sentido, a fratura entre pensamento e ação que parece ser própria do campo educacional, oriunda na esfera material e abrange outras dimensões da vida humana.

Assim, numa sociedade dividida em classes, o processo educativo institucionalizado é dualista e visa, mormente, legitimar a relação desigual entre governantes e subalternos. No contexto atual, Mészáros (2008, p. 45) crítica a educação formal por entendê-la como mecanismo de produção de consenso a favor de uma sociedade que se funda na lógica do capital.

[...] Uma das funções principais da educação formal nas nossas sociedades é produzir tanta conformidade ou "consenso" quanto for capaz, a partir de dentro e por meio dos seus próprios limites institucionalizados e legalmente sancionados. Esperar da sociedade mercantilizada uma sanção ativa - ou mesmo mera tolerância - de um mandato que estimule as instituições de educação formal a abraçar plenamente a grande tarefa histórica do nosso tempo, ou seja, a tarefa de romper com a lógica do capital no interesse da sobrevivência humana, seria um milagre monumental [...]. 
Conforme esse autor húngaro, a educação institucional tem como principais propósitos produzir o consenso a fim de legitimar os interesses burgueses e fornecer mão de obra relativamente qualificada para a produção e a expansão do sistema vigente. Afirma ainda que acreditar que as reformas educacionais apresentadas nos últimos anos mudarão as regras capitalistas é esperar por um grande milagre. Porém, como milagres não existem na sociedade burguesa, as ações promovidas no âmbito educacional escolar e extraescolar precisam ser direcionadas para a superação radical da lógica do capital.

O filosofo sardo via na educação institucional um aparato de manutenção permanente da ordem do capital. Por outro lado, Gramsci enxergava na educação extraescolar, sobretudo oferecida nos partidos e sindicatos políticos, um grande instrumento de luta da classe trabalhadora.

Em síntese, a educação na perspectiva gramsciana é processo mediador para problematizar o ordenamento do capital e fortalecer a luta contra o pensamento único fascista, que propaga a intolerância às instituições e às subjetividades antagônicas. Nesse sentido, os escritos gramscianos podem contribuir tanto para entendermos o fenômeno fascista que emergiu no início do século XX na Itália, quanto para fundamentar a luta de instituições e movimentos sociais que, no contexto atual, combatem o negacionismo, o neofascismo que defende o ataque aos grupos subalternos, a discriminação e a ideologia de extrema direita que se expressa, aparentemente, como neutra.

\section{CONSIDERAÇÕES FINAIS}

Na sociedade de classes a educação, sobretudo a escolar, é objeto de disputa de grupos que defendem interesses antagônicos na arena social. Os que vencem essa disputa acabam determinando o modelo educacional conforme seus interesses. Desse embate, emergem uma educação dualista que expressa em si a contradição fundamental entre governantes e governados.

Para os primeiros, a educação visa validar e reproduzir as relações de poder que mantêm a classe trabalhadora na condição subalterna. Nessa direção, educa-se para a manutenção do ordenamento social vigente, que é tido como o ideal de cidadania, de liberdade e prosperidade. Todavia, esse mundo idealizado e defendido pelos intelectuais 
orgânicos comprometidos com a ordem em vigor, manifesta-se como negação da humanização dos sujeitos subalternos.

Para esses, a sociedade capitalista, fundada na lógica de extração compulsiva de mais-valia, não é sinônima de liberdade, mas de validação da sua condição de subordinados nas correlações de força. Submissão que resulta de um longo processo de coerção em que a legalidade burguesa legitima e estabelece os princípios, as normas e os valores a serem adotados pelos sujeitos históricos, como também pelo consenso por meio do qual os subalternos absorvem, passiva ou ativamente, a concepção de mundo dominante e dirigente,

Essa absorção da ideologia da classe governante pelos governados requer um determinado modelo de educação para que seja difundida e adotada como pensamento hegemônico. Para Gramsci, esse tipo de educação não apenas valida o poder dominante, como também contribui para que os simples não se reconheçam como mestres de si mesmos.

Nessa direção, o pensador sardo compreende que a educação fascista é um modelo que aprofunda a condição de subalternidade, que é peculiar da sociedade de classe. Isso ocorre, porque defende o discurso de nação versus classe social, a dicotomia teoria e prática, a naturalização da desigualdade social, a supremacia da elite patriótica, a conquista de um passado glorioso e o ataque a qualquer pensamento crítico.

$\mathrm{Na}$ contracorrente, Gramsci propõe uma educação da classe subalterna que desvele o fascismo como uma ideologia anuladora das vozes antagônicas. Nessa perspectiva, educar é sinônimo de elevação crítica do ser humano, que se compromete com a construção de uma nova forma de sociabilidade humana. Assim, o processo educativo dos simples visa contribuir para torná-los sujeitos históricos construtores de uma sociedade regulada pelos produtores da riqueza material e cultural.

Por fim, convém ressaltar que o debate educacional em Gramsci é relevante para o cenário histórico atual, porque problematiza a lógica do capital e o sistema capitalista que nutrem a condição de subalternidade da classe da trabalhadora, instiga os simples a lutarem pela conquista da sociedade emancipada, articula dialeticamente subjetividade e objetividade, articula disciplina e espontaneidade, combate o discurso fascista intolerante e nos ensina a lutar contra as ideologias de cunho autoritário, negacionista, xenofóbico e racista tão presentes nos mais diversos países. 


\section{REFERÊNCIAS}

DIAS, Edmundo Fernandes. Hegemonia: racionalidade que se faz história. In: DIAS, Edmundo (org.). O outro Gramsci. 2.ed. SP: Xamã, 1996. p. 10-80.

GIL, Antonio Carlos. Como elaborar projetos de pesquisa. 4. ed. São Paulo: Atlas, 2002.

GRAMSCI, Antonio. Escritos Políticos (1910-1920). Rio de Janeiro: Civilização Brasileira, 2004, V.1.

Escritos políticos (1921 -1926). Organização e tradução de Carlos Nelson Coutinho. Rio de Janeiro: Civilização Brasileira, 2004.

Caderno 25 (1934): Às margens da história. (História dos grupos sociais subalternos). In: Cadernos do Cárcere: Volume 5. O Resorgimento. Notas sobre a história da Itália. Tradução de Luiz Sérgio Henriques. $4^{\mathrm{a}}$ ed. RJ: Civilização Brasileira, 2015 .

LESSA, Sérgio. O estudo e o momento histórico. In: O revolucionário e o estudo: por que não estudamos?. São Paulo: Instituto Lukcás, 2014.

MORAIS, Roque. Uma Tempestade de Luz: a compreensão possibilitada pela Análise Textual Discursiva. Ciência e Educação, v. 9, p. 191 -211.2003.

MÉSZÁROS, István. A educação para além do capital . Tradução Isa Tavares. 2.ed. São Paulo : Boitempo, 2008.

SANTOS, Pedro. Educar para quê?: uma análise gramsciana da prática do educador social com crianças e adolescentes. 2017. 297 f. Tese (Doutorado em Educação) Universidade Federal do Ceará, Faculdade de Educação, Programa de Pós-Graduação em Educação, Fortaleza, 2017.

SEMERARO, Giovanni. Intelectuais, Educação e Escola: Um estudo do Caderno 12 de Antonio Gramsci. Tradução Maria Margarida Machado. São Paulo: Expressão Popular, 2021. 